\title{
Chemical changes in PCPDTBT:PCBM solar cells using XPS and TOF-SIMS and use of inverted device structure for improving lifetime performance
}

\author{
J.Kettle ${ }^{a^{*}}$, H. Waters ${ }^{a}$, Z. Ding ${ }^{a}$, M. Horie ${ }^{b}$, G.C. Smith ${ }^{c}$
}

a School of Electronic Engineering, University of Bangor, Dean St, Bangor, LL57 1UT, Wales, UK, *E-mail: j.kettle@bangor.ac.uk

b Department of Chemical Engineering, National Tsing Hua University, 101, Sec. 2, Kuang-Fu Road, Hsinchu, Taiwan 30013, ROC

c Department of Natural Sciences, University of Chester, Thornton Science Park, Chester CH2 4NU, UK

\begin{abstract}
Analysis of the degradation routes for poly[(4,4-bis(2-ethylhexyl)-cyclopenta-[2,1- $b ; 3,4-$ $b^{\prime}$ ]dithiophene)-2,6-diyl-alt-2,1,3-benzothiadiazole-4,7-diyl] (PCPDTBT)-based solar cells under illumination and in the presence of air have been conducted using a combination of X-ray Photoelectron Spectroscopy (XPS), Time-Of-Flight Secondary Ion Mass Spectrometry (TOF-SIMs) and solar cell device data. After ageing, XPS studies show that PCPDTBT appears as an oxygencontaining polymer, with data indicating that a break-up in the aromatic rings, formation of sulphates at the thiophene ring, chain scission in the polymer backbone and also loss of side chains. XPS studies have also been conducted on Phenyl-C71-butyric acid methyl ester $\left(\mathrm{PC}_{71} \mathrm{BM}\right)$ films and show a breakage of the fullerene cage, loss of molecular shape and oxidation of carbon atoms in the fullerene cage and side chains after ageing. XPS studies on active layers blends of PCPDTBT and PCBM also show significant changes in the vertical composition during ageing, with increased enrichment of PCPDTBT observed at the top surface and that the use of a processing additive (ODT) has a negative impact on the morphological stability. Based on these studies, it shown that inverted structures are better suited than non-inverted devices for PCPDTBT:PCBM solar cells. An additional advantage of inverted devices is shown using TOF-SIMS; electrode degradation during ageing experiments leads to migration of indium and tin ions into the active layer in non-inverted devices, but is eliminated for inverted devices.
\end{abstract}

Keywords: Organic photovoltaics, degradation, x-ray photoelectron spectroscopy, inverted solar cells, time of flight secondary ion mass spectrometry 


\section{Highlights}

- XPS studies show chemical degradation pathways in PCPDTBT and fullerene derivatives

- Processing additives are shown to lead to worse morphological stability

- Inverted cell structures prevent electrode migration into the active layer

- Conclusions provide wider insight into degradation in other OPV material systems

\section{Introduction}

Organic Photovoltaics (OPVs) provide the possibility of low cost, solution processible solar electricity generation. Whilst performances have steadily improved, OPVs still exhibit poor lifetimes. Analytical techniques such as x-ray photoelectron spectroscopy (XPS) and time-of-flight secondary ion mass Spectrometry (TOF-SIMS) have been undertaken by a number of groups to evaluate chemical changes in OPV materials with time. Unsurprisingly, most work using this technique has focused on the Poly(3-hexylthiophene-2,5-diyl) (P3HT) system, as this is one of the most commonly reported materials [1]. However, P3HT lacks the broad absorption profile needed for collection of a large proportion of the solar spectrum which is required for better solar cell performance. An example of a new material that has been introduced as a candidate for higher performance solar cells is poly $[(4,4-$ bis(2-ethylhexyl)-cyclopenta-[2,1-b;3,4- $b^{\prime}$ ]dithiophene)-2,6-diyl-alt-2,1,3-benzothiadiazole-4,7-diyl], PCPDTBT [2-3]. PCPDTBT is a "push-pull" copolymer, which uses alternating electronwithdrawing and electron-donating components to decrease the band gap [2,3].

X-ray photoelectron spectroscopy (XPS) has often been used for characterising chemical changes in active layer material with time. For example, Hintz et al. looked at the effect of exposing P3HT immediately to oxygen under dark and illumination and showed that both physisorbed and photo-oxidised oxygen is present [4]. Seo et al studied the longer term degradation in more detail and suggested the formation of sulfoxide (R-SO-R) on the sulphur atom of the thiophene ring [5]. Changes in the oxidised C1s spectra were mostly attributed to $\mathrm{C}-\mathrm{OH}$ (alpha-unsaturated alcohol) on the side-chain, suggesting conservation of the ring structure. Likewise, Krebs et al studied long-term degradation in $\mathrm{P} 3 \mathrm{HT}: \mathrm{PC}_{61} \mathrm{BM}$ samples as a function of time with illumination at $1 \mathrm{Sun}\left(1000 \mathrm{~W} / \mathrm{m}^{2}\right)$ [6]. Broadening of the Sp2 peak was interpreted as indicating chain scission between the thiophene units in the polymer backbone, or the loss of side-chains. At longer exposure times, it was shown that the aromatic structure was broken and R-SOx groups formed. New C1s peak components also emerged due to oxygenated carbon species, particularly R-COOH [6].

Whilst most work has been undertaken on P3HT, Poly[ $N$-9'-heptadecanyl-2,7-carbazole-alt5,5-(4',7'-di-2-thienyl-2', 1',3'-benzothiadiazole)], (PCDTBT) has been also studied [7] and showed no significant short terms peak shifts for C1s and S2p. Other reports using XPS to study degradation included focusing on the fullerene derivative $[8,9]$. The studies showed that oxygen uptake increased 
during exposure and suggested that the $\mathrm{PC}_{61} \mathrm{BM}$ undergoes both temporary and permanent chemical reactions with oxygen.

In this paper, XPS data is presented to show the chemical changes that occur in PCPDTBT under illumination and in the presence of air. To understand the changes that occur within active layers, films of $\mathrm{PC}_{61} \mathrm{BM}$ and $\mathrm{PC}_{71} \mathrm{BM}$ have also been studied. The results show the processing conditions; in particular the use of processing additives, has a major impact on the lifetime stability of the devices. Based on these studies, it is shown that inverted devices possess better lifetime stability that conventional devices. Additional time-of-flight secondary ion mass spectrometry (TOF-SIMS) analysis has been conducted on aged inverted and non-inverted devices. Non-inverted devices show significant migration of indium and tin ions to the top of the polymer surface, which is eliminated by using an inverted structure.

\section{Experimental}

\subsection{Materials preparation}

Samples were prepared on glass substrates which were cleaned prior to coating. To study the changes in PCPDTBT-devices with time, six different samples were prepared. The first sample consists of neat PCPDTBT film, to allow the polymer degradation to be studied in isolation. PCPDTBT was synthesised in-house and possesses 2-ethylhexyl solubilising side chains [10]. PCPDTBT is normally blended with an acceptor material such as a fullerene derivative in OPV active layers. Therefore, two samples consisting of pristine [6,6]-Phenyl-C71-butyric acid methyl ester $\left(\mathrm{PC}_{71} \mathrm{BM}\right)$, which was purchased from Nano-C Inc. Finally, three layers were also prepared whereby the polymer was mixed with a fullerene derivative to replicate the active layer composition in a device. This included blending PCPDTBT with with $\mathrm{PC}_{71} \mathrm{BM}$ and also with $\mathrm{PC}_{71} \mathrm{BM}$ and also the processing additive 1,8 Octanedithiol (ODT).

ODT or similar alkanethiols are used in almost all reports of high efficiency OPVs and acts as a second non-reacting solvent. It has been shown that the incorporation of a few volume percent of ODT into the blend improves the Power Conversion Efficiency (PCE) by about a factor of two. It does this by modifying the morphology and controlling the phase separation between the donor and acceptor components [10]. Reports indicate that ODT leads to enhanced connectivity of $\mathrm{PC}_{71} \mathrm{BM}$ networks [11], a small increase in polymer crystallinity [12], reduced charge recombination and reduced charge carrier loss [13]. The blends were mixed using PCPDTBT and $\mathrm{PC}_{71} \mathrm{BM}$ with weight ratios 1:3, respectively, and were mixed with chlorobenzene solvent using a concentration of $30 \mathrm{mg} / \mathrm{mL}$. For layers with additives, ODT was added with a concentration of $24 \mathrm{mg} / \mathrm{mL}$. Prior to coating, all blends were allowed to dissolve for 24 hours on a hot plate stirrer and filtered using a 0.45 $\mu \mathrm{m}$ PTFE filter.

All coatings were undertaken in a glovebox and annealed at $80^{\circ} \mathrm{C}$ for 30 minutes to remove any residual solvent; a procedure optimised for device fabrication [10]. After an initial XPS testing at, 
the samples were aged by light soaking non-encapsulated films for 300 hours using a Class AAA solar simulator, which was calibrated at 1 Sun of irradiance. The ageing was conducted in an airconditioned room with relative humidity of $35 \% \pm 5$ and ambient temperature of $20^{\circ} \mathrm{C} \pm 5$.

Subsequently, the samples were re-measured using XPS to evaluate changes in the chemical structure at intervals of 25,100 and 300 hours of testing.

\subsection{XPS and TOF-SIMS experiments}

The XPS data were acquired using a bespoke ultra-high vacuum system fitted with a Specs GmbH Focus 500 monochromated Al Ka X-ray source, Specs GmbH Phoibos $150 \mathrm{~mm}$ mean radius hemispherical analyser with 9-channeltron detection, and a Specs GmbH FG20 charge neutralising electron gun. Survey spectra were acquired over the binding energy range $1100-0 \mathrm{eV}$ using a pass energy of $50 \mathrm{eV}$ and high resolution scans were made over the $\mathrm{C} 1 \mathrm{~s}$ and $\mathrm{O} 1 \mathrm{~s}$ lines using a pass energy of $15 \mathrm{eV}$. In each case, the analysis was an area-average over a region approximately $2 \mathrm{~mm}$ in diameter on the sample surface. The energy scale of the instrument is calibrated according to ISO standard 15472, and the intensity scale is calibrated using an in-house method traceable to the UK National Physical Laboratory.

TOF-SIMs imaging was conducted using a using a $25 \mathrm{kV}$ pulsed gallium ion beam with a Phi Thift III. A low current pulsed beam was used, which prevents sputtering of the surface sample. Imaging was conducted over $1.8 \mathrm{~mm} \times 1.8 \mathrm{~mm}$ surfaces using a mosaic function to demonstrate that changes in material composition were not confined to a small area on the sample surface.

\subsection{Device fabrication}

For all devices, the same blend as described in the XPS experiments was used. Initially, indium tin oxide (ITO) coated glass substrates $\left(\mathrm{R}_{\mathrm{s}}=16 \Omega\right.$ /square) were cleaned using solvents, which was supplied by Psiotec ltd., UK. For inverted devices, a 20nm thick layer of zinc oxide ( $\mathrm{ZnO}$ ) film was deposited on ITO/glass substrate in a sputtering system (Leybold Univex), to operate as an electron transport layer (ETL). The ZnO sputter target was purchased from Fourteen technology ltd., Wales). The active layers were applied by spin-casting from a $60^{\circ} \mathrm{C}$ solution $(2500 \mathrm{rpm}$ for 60 seconds). Finally, thermal evaporation of the anode was performed through a shadow mask to define device area of $0.1 \mathrm{~cm}^{2}$ and consisted of $10 \mathrm{~nm}$ of molybdenum trioxide $\left(\mathrm{MoO}_{3}\right)$ and $100 \mathrm{~nm}$ of silver $(\mathrm{Ag})$.

For non-inverted devices, a 40nm PEDOT:PSS layer (Ossila ltd., UK, code: AI4083) was deposited using spin coating and dried at $120^{\circ} \mathrm{C}$ for 30 minutes. The active layer was prepared using an identical manner to the inverted devices. Finally, the cathode electrode was deposited, which consisted of $8 \mathrm{~nm}$ calcium (Ca) followed by 100nm of Aluminium (Al). All materials for evaporation were supplied by K-Tech ltd., UK.

Devices were tested using a Newport solar simulator with $100 \mathrm{mWcm}^{-2}$ AM1.5G output (calibrated using a silicon reference cell from RERA in the Netherlands). For ageing of devices, light 
soaking was undertaken using an identical methodology to the XPS sample ageing as in section 2.1. Therefore, the devices were non-encapsulated and the lifetime measurements were undertaken in an air-conditioned room with relative humidity of $35 \% \pm 5$ and ambient temperature of $20^{\circ} \mathrm{C} \pm 5$. Devices were kept at open circuit in between measurements and I-V measurements were made every 30 minutes. This was conducted in accordance with ISOS-L-2 standards [12].

\section{3: XPS analysis of chemical changes with ageing}

\subsection{PCPDTBT chemical changes}

PCPDTBT films were prepared as described and evaluated by XPS using stoichiometry to analyse the relative changes in the surface composition which occur during light soaking. Table 1 shows the $\%$ atom concentration for films of PCPDTBT at $0,25,100$ and 300 hours. Based on the chemical structure of PCPDTBT, no oxygen $(\mathrm{O})$ should be present at 0 hours; however, a small amount is present, suggesting some oxidation of the material before preparation or in between coating in the glovebox and transfer to the XPS system. The composition was expected to be approximately $86 \% \mathrm{C}$, $6 \% \mathrm{~N}$ and $8 \% \mathrm{~S}$ (H is not detected by XPS). Whilst the carbon matches closely, the $\mathrm{N}$ and $\mathrm{S}$ content does not. The $\mathrm{N}: \mathrm{S}$ ratio should be $2: 3$, but is measured at 3:4 suggesting either excess $\mathrm{N}$, or possibly orientation of the molecule at the surface such that $\mathrm{N}$ is more exposed to the surface and therefore gives a greater signal.

As can be seen in Table 1, after light soaking in ambient air over a 300 hour time span, the amount of $\mathrm{O}$ and $\mathrm{N}$ is increased, with decreases in sulphur (S) and carbon (C). The observed changes in these four spectra are shown in Figure 2(a) and it appears that the most drastic changes occur within the first 100 hours of light soaking. In Figure 1(a), asymmetric curve fitting of the non-aged sample shows peaks at $284.7 \mathrm{eV}$ and $285.2 \mathrm{eV}$ for unsaturated graphite-like and hydrocarbon-like carbon, respectively. This corresponds to carbon in the CPDT and BT monomers (graphite-like), and also in the 2-ethylhexyl side-chains (hydrocarbon-like). The peak at $286.3 \mathrm{eV}$ is attributable to $\mathrm{C}-\mathrm{N}$ or $\mathrm{C}-\mathrm{S}$ bonds on the BT monomer unit. The remaining peaks are due to some low level oxidation and photoemission from the aromatic rings.

Following light-soaking for 300 hours, the $\mathrm{C} 1 \mathrm{~s}$ spectrum appears typical of an oxygencontaining polymer with well-defined symmetric components at $285 \mathrm{eV}(\mathrm{C}-\mathrm{C}), 286.5 \mathrm{eV}(\mathrm{C}-\mathrm{O}), 287.9$ $\mathrm{eV}(\mathrm{C}=\mathrm{O})$ and $289.2 \mathrm{eV}(\mathrm{COO}-$ or $\mathrm{C}(=\mathrm{O}) \mathrm{O})[1(\mathrm{~b})]$. These peaks are all observed in the data at 25 and 100 hours, with the curve fitting data shown in SI-1. The lack of asymmetric peaks and shake-up structures indicates that a break-up of aromatic rings has occurred and a significant increase in the oxidised carbon present in the polymer. This is supported by the peak broadening of the $\mathrm{C} 1 \mathrm{~s} \mathrm{sp} 2$ component, which can be ascribed to chain scission between the CPDT and BT unit in the polymer backbone and also oxidation and loss of side chains. In an OPV or OFET, this might be expected to lead to a severe decrease in OPV performance, leading to the inability of the polymer to transfer charge. The change in relative intensity of the $C$ 1s spectrum is shown in Figure 2(b). Interestingly, a 
decrease is initially observed $286.5 \mathrm{eV}(\mathrm{C}-\mathrm{O})$ which is matched by a rise in the $287.9 \mathrm{eV}(\mathrm{C}=\mathrm{O})$ peak in the first 25 hours. Subsequent light soaking leads to a decrease in the $\mathrm{C}=\mathrm{O}$ peak and increase in the C-O peak, whereas the carboxyl (COO-) appears to rise steadily during the light soaking tests. Based on this data, it can be concluded that the side chain and polymer is first of all oxidising (within the first 25 hours). Subsequently, these oxidised species are forming sites which then degrade to form carboxylic acid, carbonyl, or hydroxyl groups.

The Nitrogen $1 \mathrm{~s}$ spectrum at 0 hours showed a single peak at $399.9 \mathrm{eV}$ corresponding to the $\mathrm{C}-\mathrm{N}-\mathrm{S}$ in the BT monomer [figure 1(c)]. After light soaking for 300 hours, the $\mathrm{N} 1 \mathrm{~s}$ peak has decreased in intensity and split into two peaks at $399.9 \mathrm{eV}$ and $402 \mathrm{eV}$. The new second component at $\sim 402 \mathrm{eV}$ and indicates possible $\mathrm{N}-\mathrm{O}$ or quaternary $\mathrm{N}$ [figure 1(d)] formation. This could indicate two possible chemical changes; firstly the original $\mathrm{N}$ within the BT unit is oxidising during light soaking. Whilst $\mathrm{N}$ within the BT unit is perceived to be stable [ref], the decrease in the intensity supports this view. One possibility that cannot be ruled out is due to change in the absorption of $\mathrm{N}$ from the atmosphere onto the polymer. XPS measure cannot distinguish between these two possibilities. This change follow an expected trend with time [Figure 2(c)], where the intensity of the $399.9 \mathrm{eV}$ decreases rapidly in the first 25 hours and slower over the following hours of testing. This is accompanied with a rise in the $402 \mathrm{eV}$ peak.

The $S$ content was observed from the $S 2 p$ peaks and fresh samples show two $2 p$ doublets as shown in figure $1(\mathrm{e})$. The first doublet, with the $2 \mathrm{p}_{3 / 2}$ peak at $\sim 164 \mathrm{eV}$ corresponds to carbon-bonded $\mathrm{S}$, attributable to the $\mathrm{S}$ in the aromatic rings of the PCPDTBT molecular structure. The second component, at approximately half the intensity and with the $2 \mathrm{p}_{3 / 2}$ peak at $\sim 165.8 \mathrm{eV}$, corresponds to $\mathrm{S}$ in the more polar N-bonded position. The relative intensity ratio of these two components corresponds well with their relative proportion in the PCPDTBT molecule. A decrease in relative $\mathrm{S}$ content is observed (Table 1); which is equated to the substantial increase in O uptake. After ageing, the $S(2 p)$ region shows more complex structure as shown in figure 1(f). The original first two doublets are still

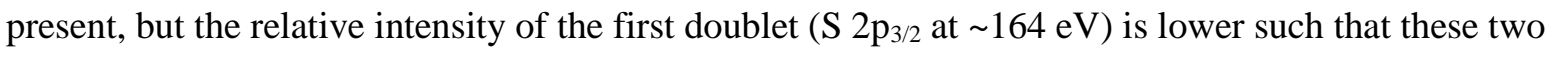
doublets are now approximately the same in relative intensity. A third doublet is now present, with the $2 p_{3 / 2}$ component at $\sim 168.4 \mathrm{eV}$ and corresponds to $\mathrm{S}$ in a fully oxidised sulphate environment, $\mathrm{SO}_{4}{ }^{2-}$.This is consistent with the view of Krebs [6], who considered that at longer exposure times it is likely for the aromatic structure to be broken and the formation of $\mathrm{R}-\mathrm{SO}_{\mathrm{x}}$. Shown in figure 2(d) is how the $\mathrm{S} 2 \mathrm{p}$ peaks change with time. Interestingly, the $2 \mathrm{p}_{3 / 2}$ peak at $\sim 164 \mathrm{eV}$ (S-C) peak decreases quicker in the first 25 hours than the $2 \mathrm{p}_{3 / 2}$ peak at $\sim 165.8 \mathrm{eV}(\mathrm{S}-\mathrm{N})$ peak. This indicates that the $\mathrm{S}$ content in the CPDT unit of the co-polymer is the less stable than the BT unit, supporting other views that the BT is a relative stable unit.

Negligible levels of oxygen in PCPDTBT at 0 hours were found (hence the curve fitting is not shown), however figure $1(\mathrm{~g})$ shows two peaks after light-soaking for 300 hours. The peaks at $532 \mathrm{eV}$ and $533 \mathrm{eV}$ correspond to $\mathrm{C}=\mathrm{O}$ and $\mathrm{C}-\mathrm{O}$ bonds, respectively, with $\mathrm{C}=\mathrm{O}$ at a higher proportion, in 
agreement with the $\mathrm{C} 1 \mathrm{~s}$ measurements. The formation of carbonyl groups has been shown in other material systems. Carbonyl groups have been shown to be charge traps in OPVs before, leading to exciton quenching [12].

Based upon the findings of the XPS analysis, Figure 3 summarises the possible changes of the chemical structure of PCPDTBT after light soaking, showing the three primary changes including the ring structure decomposing into $\mathrm{R}-\mathrm{SO}_{\mathrm{x}}$.

\subsection{Study of $\mathrm{PC}_{71} \mathrm{BM}$ chemical changes}

Films of $\mathrm{PC}_{71} \mathrm{BM}$ were prepared and tested as described in section 2.3. Table 2 shows the $\%$ atom concentration for films of $\mathrm{PC}_{71} \mathrm{BM}$ at 0,25 and 100 and 300 hours. Stoichiometry would suggest that oxygen contents were supposed to be at a concentration of $2.4 \%$ for $\mathrm{PC}_{71} \mathrm{BM}$, which is present in the side-chains; however a slightly higher level of $3.6 \%$ was measured at 0 hours, suggesting some oxidation prior to transfer into the XPS.

Upon light-soaking there is significant oxygen uptake in $\mathrm{PC}_{71} \mathrm{BM}$, rising to $20.26 \%$ of the total concentration. Additionally the nitrogen content goes from a negligible level that is below the sensitivity of the XPS to $1.06 \%$ for $\mathrm{PC}_{71} \mathrm{BM}$. Sulphur also slightly increases from a negligible level to $0.16 \%$. Data has also been obtained for $\mathrm{PC}_{61} \mathrm{BM}$, which is of interest to the scientific community and is shown in SI-2. It is implied that $\mathrm{PC}_{71} \mathrm{BM}$ has greater stability than $\mathrm{PC}_{61} \mathrm{BM}$, as it possesses a lower uptake of oxygen, nitrogen and sulphur.

The exact chemical changes, hence degradation mechanisms, can be deduced from the individual spectra for the respective elements. Figure 4(a) shows the initial XPS spectrum for carbon $(\mathrm{C} 1 \mathrm{~s})$, of which there is a strong and defined peak at $285 \mathrm{eV}$, corresponding to $\mathrm{C}-\mathrm{C}$ bonds in the main $\mathrm{C}_{70}$ structure. The peak shape is typical of partially-ordered graphite-like materials, as is the low intensity higher binding energy structure, attributed mainly to energy losses and partially-developed plasmon-like structures. There are also peaks at $286.7 \mathrm{eV}$ and $288.8 \mathrm{eV}$, which are attributed to $\mathrm{O}-\mathrm{C}=\mathrm{O}$ and $-\mathrm{O}-\mathrm{CH}_{3}$ respectively. Upon light-soaking the intensities of the peaks shown in figure 4(a) have increased considerably, and can be seen in figure $4(\mathrm{~b})$. The main peak at $285 \mathrm{eV}$, corresponding to C-C bonds, has now split up into two components of $\mathrm{sp} 2$ and $\mathrm{sp} 3$ carbon (from $\mathrm{C} 1 \mathrm{~s}$ ), which correspond to graphite-like and hydrocarbon-like carbon. This indicates the breakage of the $\mathrm{C}_{60}$ and $\mathrm{C}_{70}$ fullerene and loss of molecular shape. As the shape is tied to ability for charge transfer, this could lead to significant decrease in performance within a solar cell. Other peaks present with increased intensities have binding energies of $286.7 \mathrm{eV}, 288 \mathrm{eV}$ and $289.2 \mathrm{eV}$, corresponding to $\mathrm{C}-\mathrm{O}, \mathrm{C}=\mathrm{O}$ and $\mathrm{COO}-$ respectively. Although these peaks were present in non-aged films, their significant increase indicates pronounced oxidation of $\mathrm{PC}_{71} \mathrm{BM}$.

XPS spectra for O1s before and after light-soaking (figure 4(c) and 4(d) respectively) shows the same two components at $532 \mathrm{eV}$ and $533.5 \mathrm{eV}$ for $\mathrm{C}=\mathrm{O}$ and $\mathrm{C}-\mathrm{O}$ respectively, but with different intensities. After light soaking, the peaks are much stronger, but have broadened, suggesting that the 
$\mathrm{C}-\mathrm{O}$ and $\mathrm{C}=\mathrm{O}$ bonds are present in a range of chemical environments, with subtle local variations. As well as the $\mathrm{C}-\mathrm{O}$ and $\mathrm{C}=\mathrm{O}$ present in the side-chain, it is therefore likely that $\mathrm{C}-\mathrm{O}$ and $\mathrm{C}=\mathrm{O}$ oxidation of the carbon atoms in the fullerene cage has occurred, but these cannot be readily distinguished due to the broadened peaks.

\subsection{Study of active layer compositional changes}

Data was collated from typical active layers of PCPDTBT-based solar cells. Two layers were used; PCPDTBT blended with $\mathrm{PC}_{71} \mathrm{BM}$ and finally PCPDTBT with $\mathrm{PC}_{71} \mathrm{BM}$ and the process additive, ODT. ODT is a high boiling point solvent and might remain in films after spin coating of the active layer. However, several reports show, no detectable additive remains in the film after drying under UHV [11]. All blends were prepared with $75 \%$ fullerene content, in keeping with the optimal performance in device active layers $[2,10,15]$. It is therefore likely the results will be a convolution of the XPS data from Sections 3.1 and 3.2.

The two samples measured at 0 hours show relatively similar compositions, with slightly more $\mathrm{C}$ and lower $\mathrm{O}, \mathrm{N}$ and $\mathrm{S}$ on the sample with $\mathrm{PC}_{71} \mathrm{BM}$, consistent with the higher level of $\mathrm{C}$ expected for the fullerene component of that sample. As all blends have aa $75 \%$ fullerene content, we can expect the molecular structures of PCPDTBT:PC ${ }_{61} \mathrm{BM}$ to possess $95.7 \% \mathrm{C}, 2.3 \% \mathrm{O}, 1.2 \% \mathrm{~S}$ and $0.8 \% \mathrm{~N}$, and the PCPDTBT:PC ${ }_{71} \mathrm{BM}$ to possess $96.1 \% \mathrm{C}, 2.1 \% \mathrm{O}, 1.0 \% \mathrm{~S}$ and $0.8 \% \mathrm{~N}$, but both layers exhibit higher $\mathrm{S}$ and $\mathrm{N}$ content.

\subsection{Effect of ODT inclusion on the compositional change of the active layer}

Results from a PCPDTBT with $\mathrm{PC}_{71} \mathrm{BM}$ sample with the processing additive, ODT, are included in Table 3 for comparison with films made without ODT. It is clear that higher S and N content are observed and lower $\mathrm{O}$ and $\mathrm{C}$. Whilst ODT does possess sulphur, this is almost certainly evaporated when placed in UHV [11]. Therefore, this data signifies that PCPDTBT is preferentially phase separating to the surface also, but to an even greater extent than for layers without ODT.

On ageing, the sample with ODT shows the same trend as seen for the previous samples i.e. much higher $\mathrm{O}$, higher $\mathrm{N}$, lower $\mathrm{S}$ and correspondingly lower $\mathrm{C}$. Carbon appears as an oxygencontaining hydrocarbon with little evidence of aromatic species (the curve fitting of this data is not shown). Oxygen increases in intensity and shows two broad components attributable to $\mathrm{C}=\mathrm{O}$ and $\mathrm{C}-\mathrm{O}$ with the $\mathrm{C}=\mathrm{O}$ greater in relative proportion.

To further characterize the active layer in the vertical direction, XPS measurement has been used on the top surfaces of the active layer to determine the polymer/fullerene composition. Table 3 shows the peak area ratios of the $S 2 p$ and $C$ 1s peaks for the top surfaces. Even though $\mathrm{PC}_{71} \mathrm{BM}$ contains oxygen, the $\mathrm{O} 1 \mathrm{~s}$ intensity cannot be assumed to be $\mathrm{PC}_{71} \mathrm{BM}$ due to the air contamination of sample. The volume fraction of PCPDTBT at the top layer of the blend films compared to a pure 
PCPDTBT top layer is shown in Table 3. Previous studies of polymer-fullerene blends have used these two ratios to correlate the relative polymer concentration at the top surface of the blend $[16,17]$.

From Table 3, it is found that the relative \% of PCPDTBT at 0 hours is higher than if the film was homogenously distributed; one should expect $25 \%$ relative PCPDTBT if this was the case. However, the measured concentration of PCPDTBT is 58\% for films with ODT and $35 \%$ for films without ODT. This indicates that both layers exhibit an enrichment of PCPDTBT at the surface; however, a much higher enrichment occurs at the surface for blends with ODT. This data suggests that devices made with PCPDTBT:PC ${ }_{71} \mathrm{BM}$ (with and without ODT) are better suited to inverted structures, as the concentration distribution of PCPDTBT is richer at the top surface. Therefore, by using this surface for deposition of the anode electrode, one would expect to improve the charge transfer to the electrodes. It also indicates that devices made with ODT are even better suited for inverted devices than made without ODT.

After ageing, the layers with ODT show a change in composition (around 10\% relative decrease in PCPDTBT content over the 300 hours of testing) of the top surface. However, layers without ODT show almost no change. So whilst PCPDTBT:PC ${ }_{71} \mathrm{BM}$ with ODT provides better initial conditions for inverted cells, inclusion of the additive leads to greater changes in the layer and thus, greater change in the morphology. Previous reports have indicated that ODT remains in the film after processing, due to its high boiling point $\left(270^{\circ} \mathrm{C}\right)$ and continues to dynamically alter the morphology with time [15] and this XPS data supports this view.

\section{Device analysis of chemical changes}

\section{$\underline{\text { 4.1 Device lifetime data }}$}

The XPS results suggest the advantage of the inverted device structure over the non-inverted devices both in terms of performance and lifetime. Furthermore, the XPS data suggests that the PCPDTBT:based OPVs made without ODT should provide a more stable device, irrespective of architecture. This has already been proven for non-inverted devices [15]; however this hasn't been tested for inverted devices. Therefore, OPV devices were fabricated to test this hypothesis using the experimental technique outlined in section 2.2. A schematic of the device geometries is shown in Figure 5.

The degradation behaviour of the devices under identical aging conditions is shown in Figure 6 , with open circuit voltage $\left(\mathrm{V}_{\mathrm{OC}}\right)$, short circuit current density $\left(\mathrm{J}_{\mathrm{SC}}\right)$, fill factor $(\mathrm{FF})$ and power conversion efficiency (PCE) changing with time shown. Initial performances of the devices used for these tests are shown in table 4 and exhibit the expected performance for this material system based on previous studies $[2,3,10,15]$. The performance of the inverted devices slightly exceeds that of the non-inverted ones. 
Considering first of all the non-inverted devices; these devices appear to degrade quickest. For these devices, the $\mathrm{V}_{\mathrm{OC}}$ over time is essentially unchanged with the major degradation occurring due to the FF and $\mathrm{J}_{\mathrm{SC}}$. However, the FF and $\mathrm{J}_{\mathrm{SC}}$ decrease is dissimilar for devices made with and without ODT, so the degradation at the electrodes cannot be the sole reason for the decrease in PV performance. The XPS data indicates that the devices made using ODT are likely to experience greater change in morphology. As the active layer ages, the proportion of PCPDTBT at the Ca/Al electrode surface increases and electrons are less able to transport from the active layer to the corresponding electrode. The XPS data showed that this morphological change is worse for layers with ODT, which explains the worse performance of the PCPDTBT:PC ${ }_{71} B M$ solar cell with ODT.

Data is also shown for the performance of the inverted devices; it is clear that devices last much longer, due to the relative stability of the $\mathrm{MoO}_{3} / \mathrm{Ag}$ top contact and low chemical reactivity of the ZnO ETL [19]. This is in agreement with the both the XPS data and with reports from other material systems such as P3HT and PCDTBT $[17,18]$. As with the non-inverted devices, it is clear that devices made without the processing additive possess greater lifetime than devices with additive. Inverted devices without ODT actually show remarkable stability, despite the absence of encapsulation. After the initial 'burn-in' the device performance stays constant for the duration of the experiment with the half-life ( $\left.\mathrm{t}_{1 / 2}\right)$ estimated at 1900 hours (using curve fitting). For both devices, the FF response overtime is essentially unchanged, so the PCE tends to follow the changes in the $\mathrm{J}_{\mathrm{SC}}$ and the $\mathrm{V}_{\mathrm{OC}}$. The decrease in $\mathrm{J}_{\mathrm{SC}}$ could be due to a number of mechanisms; however, based on the earlier XPS data, this is likely to be due to the chemical degradation in the PCPDTBT and PC ${ }_{71} \mathrm{BMIn}$ particular, the XPS data shows that including ODT leads to PCPDTBT enriching on the top surface with ageing, thus leading to efficient hole transport from the device into the $\mathrm{MoO}_{3} / \mathrm{Ag}$ electrode. In SI-3, data is shown for the performance of encapsulated OPVs fabricated in the same manner as the devices tested in figure 6. Encapsulated was conducted in the glovebox prior to light soaking using a UV curable epoxy supplied by Ossila ltd., UK. This data shows that devices made with ODT degrade quicker as a result of FF losses also. The supports the view of the XPS measurements; OPV devices made with ODT are more prone to morphological changes with time.

One interesting result from figure 6 is that the inverted device, processed with ODT, shows a fall in $\mathrm{V}_{\mathrm{OC}}$ with time, in contrast with the other 3 sets of device data. Whilst there are few reports of the stability of the PCPDTBT:PCBM solar cells, it is known from other materials systems such as P3HT that a drop in $\mathrm{V}_{\mathrm{OC}}$ can be equated to a modification of the HOMO level of the polymer, which is normally caused by oxygen absorption [4]. As the proportion of PCPDTBT at the top surface, when using ODT additive, is very high (see table 3), it is therefore the most susceptible component of the active layer to oxidation. In non-inverted configuration, the Ca electrode is deposited above the active layer and therefore any oxygen ingress is likely to react with the $\mathrm{Ca}$ first, so the Ca layer 'protects' the PCPDTBT from substantial oxidation and the $\mathrm{V}_{\text {OC }}$ stays approximately constant. In inverted configuration, the $\mathrm{MoO}_{3}$ is deposited above the active layer, but is air stable. Therefore, any oxygen 
ingress is likely to diffuse through the $\mathrm{MoO}_{3}$ layer and react with the polymer first, leading to increased polymer oxidation and drop in $\mathrm{V}_{\mathrm{OC}}$.

\subsection{TOF-SIMS analysis of electrode migration}

An additional advantage of inverted structures over non-inverted one is shown using TOF-SIMS imaging. Figure 7 reveals the surface elemental distribution of non-inverted/inverted cells based on PCPDTBT:PC ${ }_{71} \mathrm{BM}$ (section 3.5), both of which have been aged in air for 500 hours. Indium (In) and tin $(\mathrm{Sn})$ ions were observed on the non-inverted device surface after aging (no In/Sn were observed on fresh device surface), indicating that the electrode material is degrading and migrating through the hole transport layers and the active layer to the top surface. By comparison, there is no sign of In or Sn migration in the inverted cell.

Electrode migration is likely due to an ITO etching effect when it is exposed to PEDOT:PSS, as reported by Sharma [20, 21]. The migrated ions could result in degradation of the electrical performance by numerous mechanisms including formation of electrical trap states in PEDOT:PSS or changing of interface dipoles [20,21]. The sharp decrease of $F F$ and $J_{\text {Sc }}$ seen in the devices, section 3.5 during the first tens of hours light soaking in air (figure 6) is in agreement with the time scale of indium migration in PEDOT:PSS and the accompanied S-shaped IV reported by Sharma [21]. It worth pointing out from our TOF-SIMS observation that the In and Sn migrates further than previously thought and that migration is observed through the entire PCPDTBT:PC ${ }_{71} \mathrm{BM}$ active layer as well. The effect of such ionic impurities in the active layer is not well understood yet, but based on previous reports of metallic impurities is likely to cause a decrease in performance [10].

The inverted device, in contrast, showed no electrode migration, due to the absence of PEDOT:PSS or the 'ion blocking effect' of ZnO layer on top of ITO electrode. This demonstrates an additional advantage of inverted cell structures in PCPDTBT-based solar cells which hasn't yet been reported.

\section{Conclusion}

The data are presented shows the chemical changes that occur in PCPDTBT under illumination, in the presence of air. After ageing, the PCPDTBT appears as an oxygen-containing polymer with low asymmetric peaks and shake-up structures, indicating a break-up of aromatic rings and formation of $\mathrm{R}-\mathrm{SO}_{\mathrm{x}}$ at the thiophene ring. Broadening of the $\mathrm{S} 2 \mathrm{p}$ peak is observed, which can be ascribed to chain scission between the CPDT and BT unit in the polymer backbone and also loss of side chains. XPS studies of the PCBM films show upon ageing show a breakage of the $\mathrm{C}_{60}$ and $\mathrm{C}_{70}$ fullerene cage, loss of molecular shape and oxidation of carbon atoms in the fullerene cage and side chains. XPS studies on active layers blends of PCPDTBT and PCBM show significant changes in the vertical composition during ageing, with increased enrichment of PCPDTBT observed at the top surface of the blend. The XPS results support previous studies that show the use of a processing additive (ODT) has a major 
impact on the lifetime stability of the devices. Based on these studies, it shown that inverted solar cells possess better lifetime stability than conventional devices for PCPDTBT:PCBM solar cells. TOF-SIMs analysis has also been conducted on aged inverted and non-inverted devices. An additional advantage of inverted devices is that migration of $\mathrm{In}+$ and $\mathrm{Sn}+$ ions to the top of the polymer surface, is eliminated.

\section{Acknowledgements}

HW would like to thank Bangor University for financial support through his " 125 scholarship" from the University. ZD is supported from the "SteelPV" project, which is funded from the EC's Research Fund for Coal and Steel (RFCS) research programme under grant agreement number RFSR-CT-201400014. Finally, JK would like to thank the Royal Academy of Engineering for funding via the Newton Research Collaboration Programme (NRCP/1415/28). All authors are grateful to the scientific support and insight provided by Prof TJ Lewis, School of Electronic Engineering, Bangor University.

\section{$\underline{\text { References }}$}

[1] Dang, Minh Trung, Lionel Hirsch, and Guillaume Wantz. "P3HT: PCBM, best seller in polymer photovoltaic research." Advanced Materials 23, no. 31 (2011): 3597-3602.

[2] Peet, Jeffery, J. Y. Kim, Nelson E. Coates, Wang Li Ma, Daniel Moses, Alan J. Heeger, and Guillermo C. Bazan. "Efficiency enhancement in low-bandgap polymer solar cells by processing with alkane dithiols." Nature materials 6, no. 7 (2007): 497-500.

[3] Chang, Shu-Wei, Huw Waters, Jeff Kettle, Zi-Rui Kuo, Chun-Han Li, Chin-Yang Yu, and Masaki Horie. "Pd-Catalysed Direct Arylation Polymerisation for Synthesis of Low-Bandgap Conjugated Polymers and Photovoltaic Performance." Macromolecular rapid communications 33, no. 22 (2012): 1927-1932.

[4] Hintz, H., H-J. Egelhaaf, H. Peisert, and T. Chassé. "Photo-oxidation and ozonization of poly (3hexylthiophene) thin films as studied by UV/VIS and photoelectron spectroscopy." Polymer Degradation and Stability 95, no. 5 (2010): 818-825.

[5] Seo, Hyun Ook, Myung-Geun Jeong, Kwang-Dae Kim, Dae Han Kim, Young Dok Kim, and Dong Chan Lim. "Studies of degradation behaviors of poly (3-hexylthiophene) layers by X-ray photoelectron spectroscopy." Surface and Interface Analysis (2014). 
[6] Norrman, Kion, Morten V. Madsen, Suren A. Gevorgyan, and Frederik C. Krebs. "Degradation patterns in water and oxygen of an inverted polymer solar cell." Journal of the American Chemical Society 132, no. 47 (2010): 16883-16892.

[7] Wang, Dong Hwan, Jung Kyu Kim, Jung Hwa Seo, O. Ok Park, and Jong Hyeok Park. "Stability comparison: A PCDTBT/PC $<$ sub $>71</$ sub $>$ BM bulk-heterojunction versus a $\mathrm{P} 3 \mathrm{HT} / \mathrm{PC}<\mathrm{sub}>$ 71</sub> BM bulk-heterojunction." Solar Energy Materials and Solar Cells 101 (2012): 249-255.

[8] Bao, Qinye, Xianjie Liu, Slawomir Braun, and Mats Fahlman. "Oxygen-and Water-Based Degradation in [6, 6]-Phenyl-C61-Butyric Acid Methyl Ester (PCBM) Films." Advanced Energy Materials 4, no. 6 (2014).

[9] Tapponnier, A., I. Biaggio, and P. Gunter. "Ultrapure C 60 field-effect transistors and the effects of oxygen exposure." Applied Physics Letters 86, no. 11 (2005): 112114-112114.

[10] Kettle, J., M. Horie, L. A. Majewski, B. R. Saunders, S. Tuladhar, J. Nelson, and M. L. Turner. "Optimisation of PCPDTBT solar cells using polymer synthesis with Suzuki coupling." Solar Energy Materials and Solar Cells 95, no. 8 (2011): 2186-2193.

[11] Cho, S., Lee, J. K., Moon, J. S., Yuen, J., Lee, K., \& Heeger, A. J. (2008). Bulk heterojunction bipolar field-effect transistors processed with alkane dithiol. Organic Electronics, 9(6), 1107-1111.

[12] You, Jingbi, Letian Dou, Ken Yoshimura, Takehito Kato, Kenichiro Ohya, Tom Moriarty, Keith Emery et al. "A polymer tandem solar cell with $10.6 \%$ power conversion efficiency." Nature communications 4 (2013): 1446.

[13] Rogers, J. T., Schmidt, K., Toney, M. F., Kramer, E. J., \& Bazan, G. C. (2011). Structural order in bulk heterojunction films prepared with solvent additives. Advanced Materials, 23(20), 2284-2288.

[14] Hoke, Eric T., I. T. Sachs-Quintana, Matthew T. Lloyd, Isaac Kauvar, William R. Mateker, Alexandre M. Nardes, Craig H. Peters, Nikos Kopidakis, and Michael D. McGehee. "The role of electron affinity in determining whether fullerenes catalyze or inhibit photooxidation of polymers for solar cells." Advanced Energy Materials 2, no. 11 (2012): 1351-1357.

[15] Waters, Huw, Noel Bristow, Omar Moudam, Shu-Wei Chang, Chun-Jen Su, Wei-Ru Wu, U-Ser Jeng, Masaki Horie, and Jeff Kettle. "Effect of processing additive 1, 8-octanedithiol on the lifetime of PCPDTBT based Organic Photovoltaics." Organic Electronics 15, no. 10 (2014): 2433-2438. 
[16] Tsoi, Wing C., Steve J. Spencer, Li Yang, Amy M. Ballantyne, Patrick G. Nicholson, Alan Turnbull, Alex G. Shard et al. "Effect of crystallization on the electronic energy levels and thin film morphology of P3HT: PCBM blends." Macromolecules 44, no. 8 (2011): 2944-2952

[17] Xu, Zheng, Li-Min Chen, Guanwen Yang, Chun-Hao Huang, Jianhui Hou, Yue Wu, Gang Li, Chain-Shu Hsu, and Yang Yang. "Vertical Phase Separation in Poly (3-hexylthiophene): Fullerene Derivative Blends and its Advantage for Inverted Structure Solar Cells." Advanced Functional Materials 19, no. 8 (2009): 1227-1234.

[18] Lloyd, Matthew T., Craig H. Peters, Andres Garcia, Isaac V. Kauvar, Joseph J. Berry, Matthew O. Reese, Michael D. McGehee, David S. Ginley, and Dana C. Olson. "Influence of the hole-transport layer on the initial behavior and lifetime of inverted organic photovoltaics." Solar Energy Materials and Solar Cells 95, no. 5 (2011): 1382-1388.

[19] Jagadamma, Lethy Krishnan, Maged Abdelsamie, Abdulrahman El Labban, Emanuele Aresu, Guy O. Ngongang Ndjawa, Dalaver H. Anjum, Dongkyu Cha, Pierre M. Beaujuge, and Aram Amassian. "Efficient inverted bulk-heterojunction solar cells from low-temperature processing of amorphous ZnO buffer layers." Journal of Materials Chemistry A 2, no. 33 (2014): 13321-13331.

[20] Anirudh Sharma, Scott E. Watkins, David A. Lewis and Gunther Andersson. "Effect of indium and tin contamination on the efficiency and electronic properties of organic bulk hetero-junction solar cells." Solar Energy Materials and Solar Cells 95, no.12 (2011): 3251-3255.

[21]Anirudh Sharma, |Gunther Andersson and David A. Lewis. "Role of humidity on indium and tin migration in organic photovoltaic devices." Phys. Chem. Chem. Phys. (2011) 13, 4381-4387 
(a)

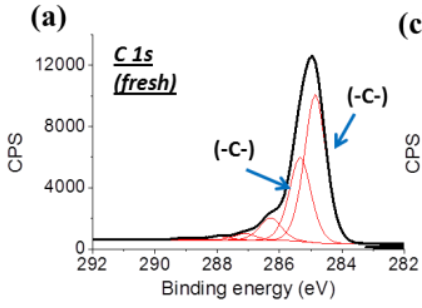

(c)

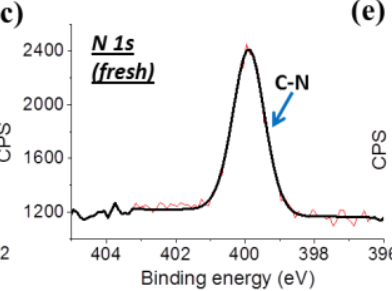

(e)
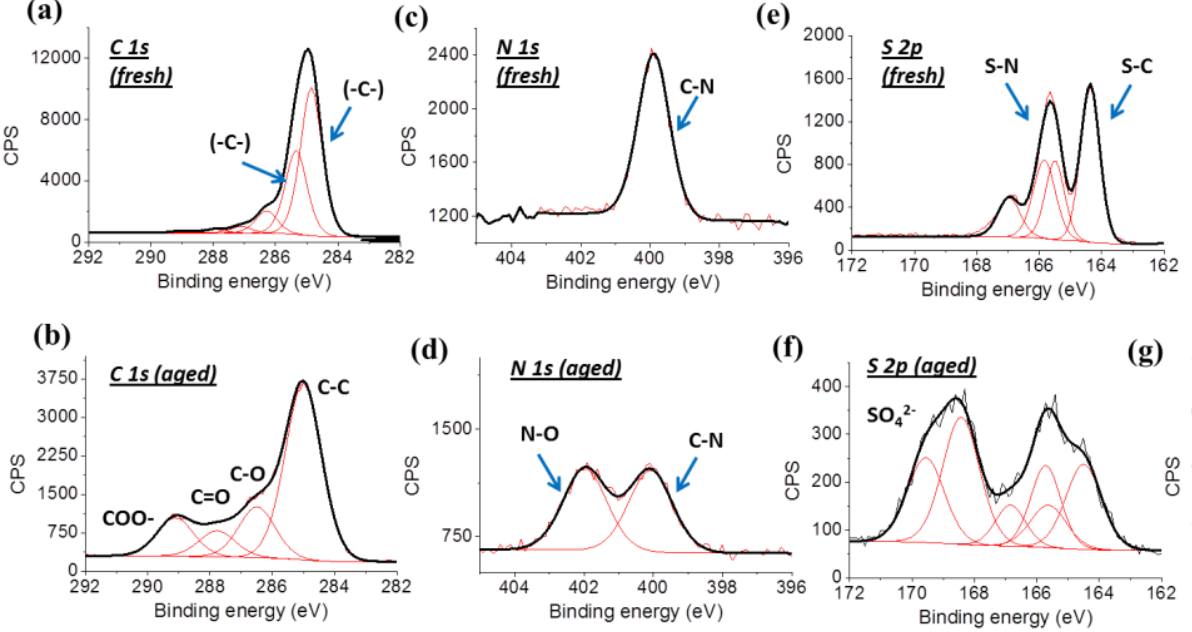

(g) 8000

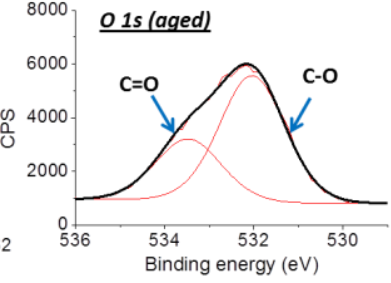

Figure 1: XPS spectra of PCPDTBT freshly prepared and aged for 300 hours using ambient air light soaking facilities. Curve fitting is shown for (a) fresh and (b) aged C(1s), (c) fresh and (d) aged N(1s) spectra, (e) fresh and (f) aged $\mathrm{S}(2 \mathrm{p})$ spectra. The spectra for $\mathrm{O}(1 \mathrm{~s})$ after ageing is also shown (no oxygen uptake of fresh samples was observed, so is not shown)
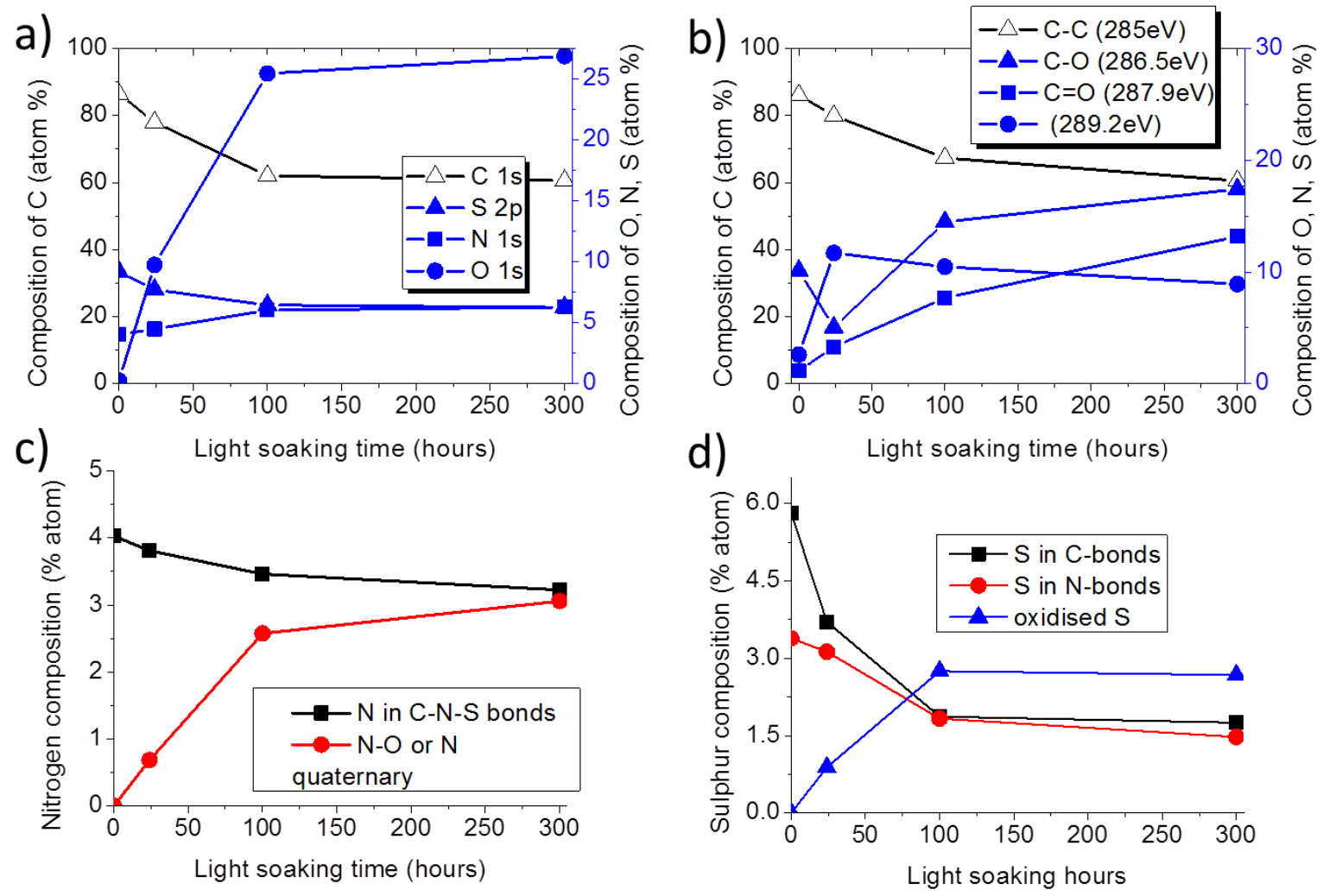

Figure 2: Data obtained from XPS spectra of PCPDTBT films as a function of ageing time, with graphs showing the evolution in a) elemental composition b) $\mathrm{C} 1 \mathrm{~s}$ peaks c) $\mathrm{N} 1 \mathrm{~s}$ peaks and d) $\mathrm{S} 2 \mathrm{p}$ 
peaks as the film is aged. Samples were aged for 300 hours using ambient air light soaking facilities, with measurements occurring at $0,25,100$ and 300 hours.

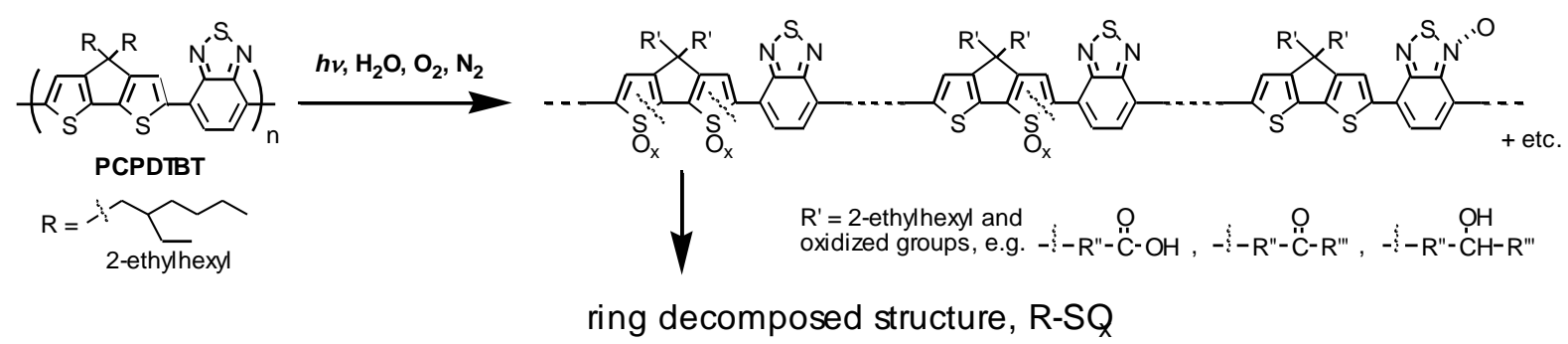

Figure 3: Plausible change of chemical structure of PCPDTBT after light soaking in normal atmospheric conditions. The side chain is oxidized to form carboxylic acid, carbonyl, or hydroxyl groups. The ring structure decomposes into R-SOx.

(a)

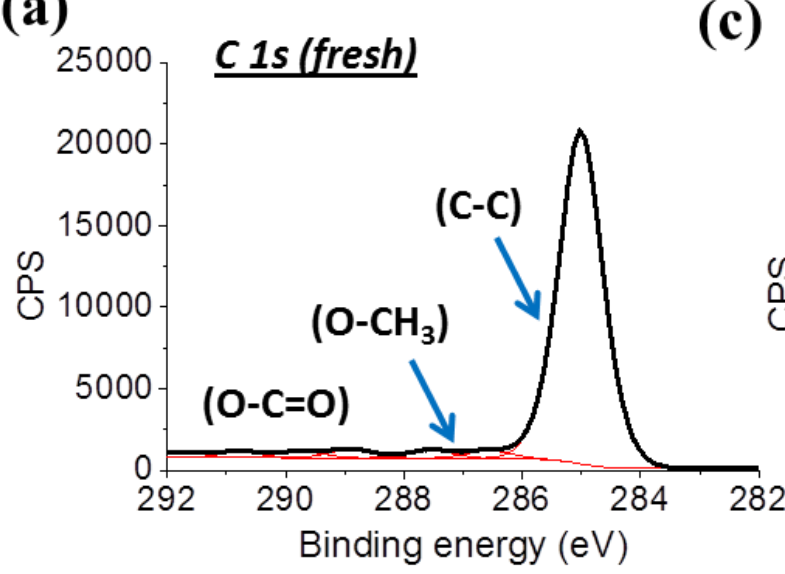

(b)

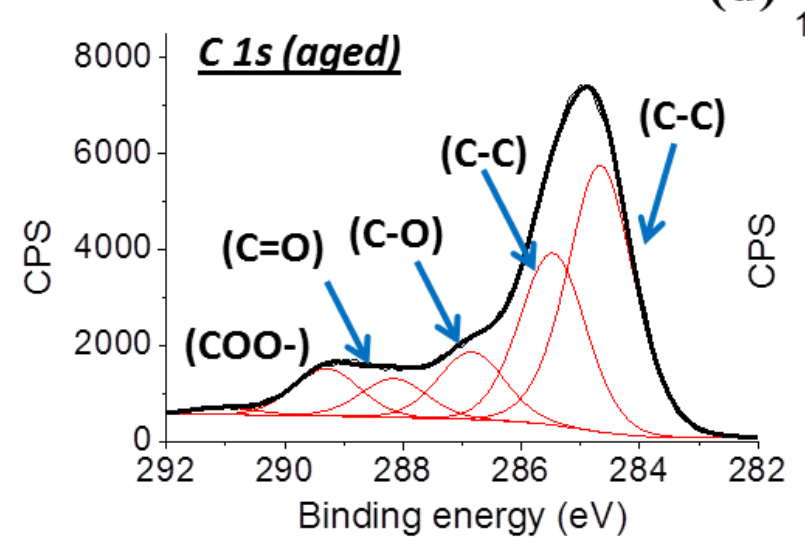

(c)

d)
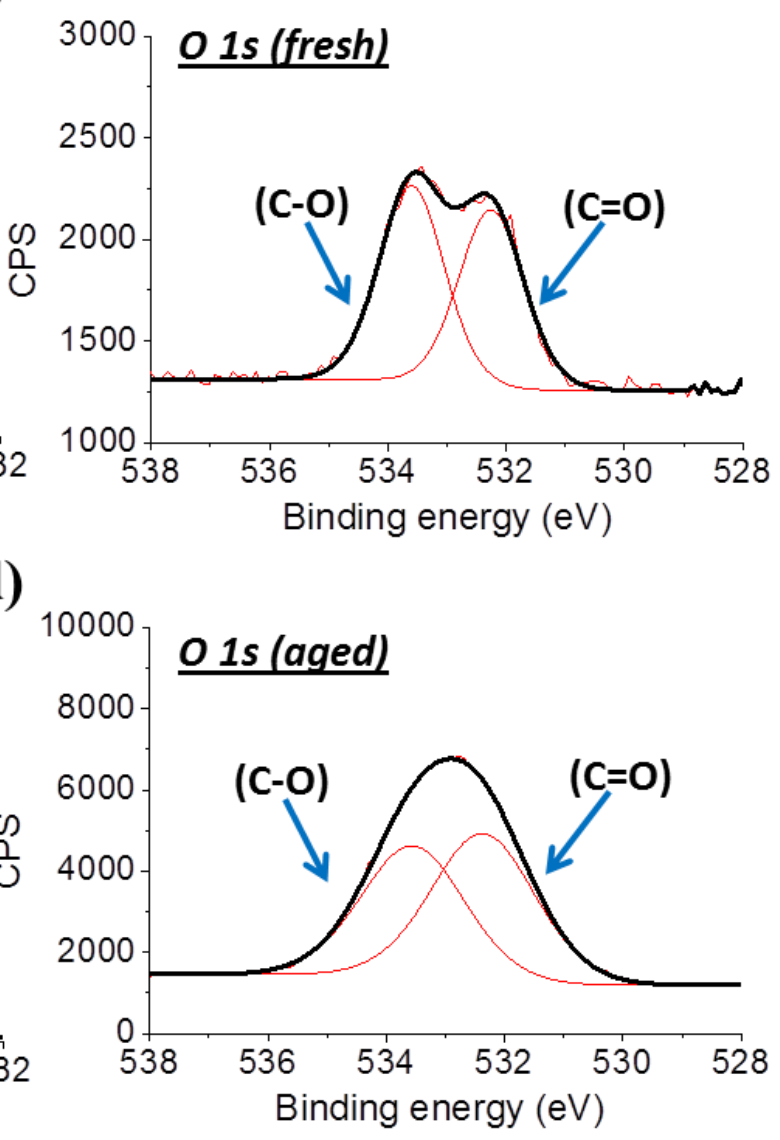
Figure 4: XPS spectra of $\mathrm{PC}_{71} \mathrm{BM}$ freshly prepared and aged for 300 hours using ambient air light soaking facilities. Curve fitting is shown for (a) fresh and (b) aged C(1s), (c) fresh and (d) aged O(1s) spectra.

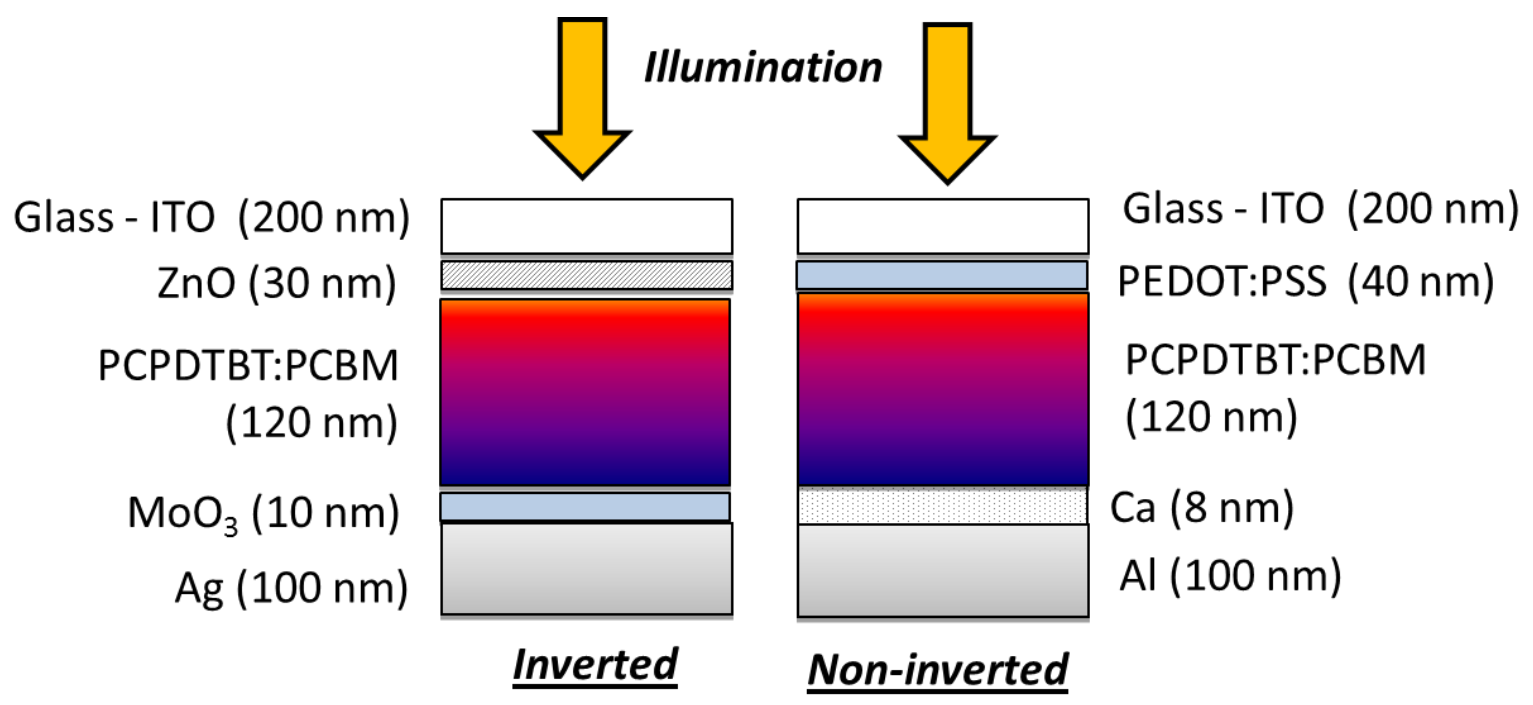

Figure 5: Schematic depiction of the (left) inverted OPV structure and (right) non-inverted OPV structure of the PV devices used 

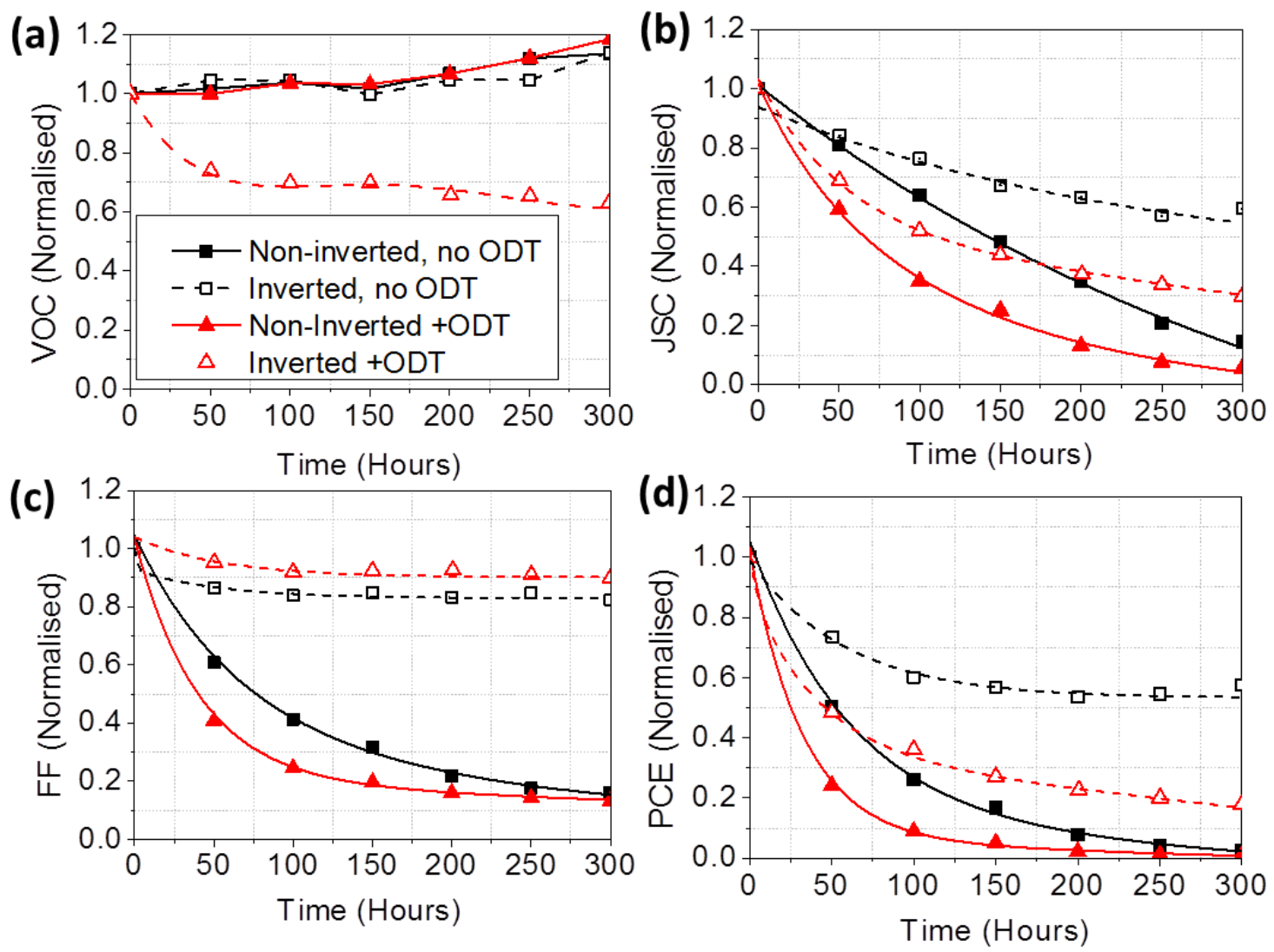

Figure 6: Device characteristics for PCPDTBT:PCBM inverted and non-inverted solar cells with and without ODT after light soaking for 300 hours under 1 sun of irradiance. The curves show the variation in (a) open-circuit voltage $\left(V_{O C}\right)$, (b) short-circuit current density $\left(J_{S C}\right),($ c) fill factor $(F F)$ and (d) power conversion efficiency $(P C E)$ and are each normalized to the initial value at the start of the aging process. 

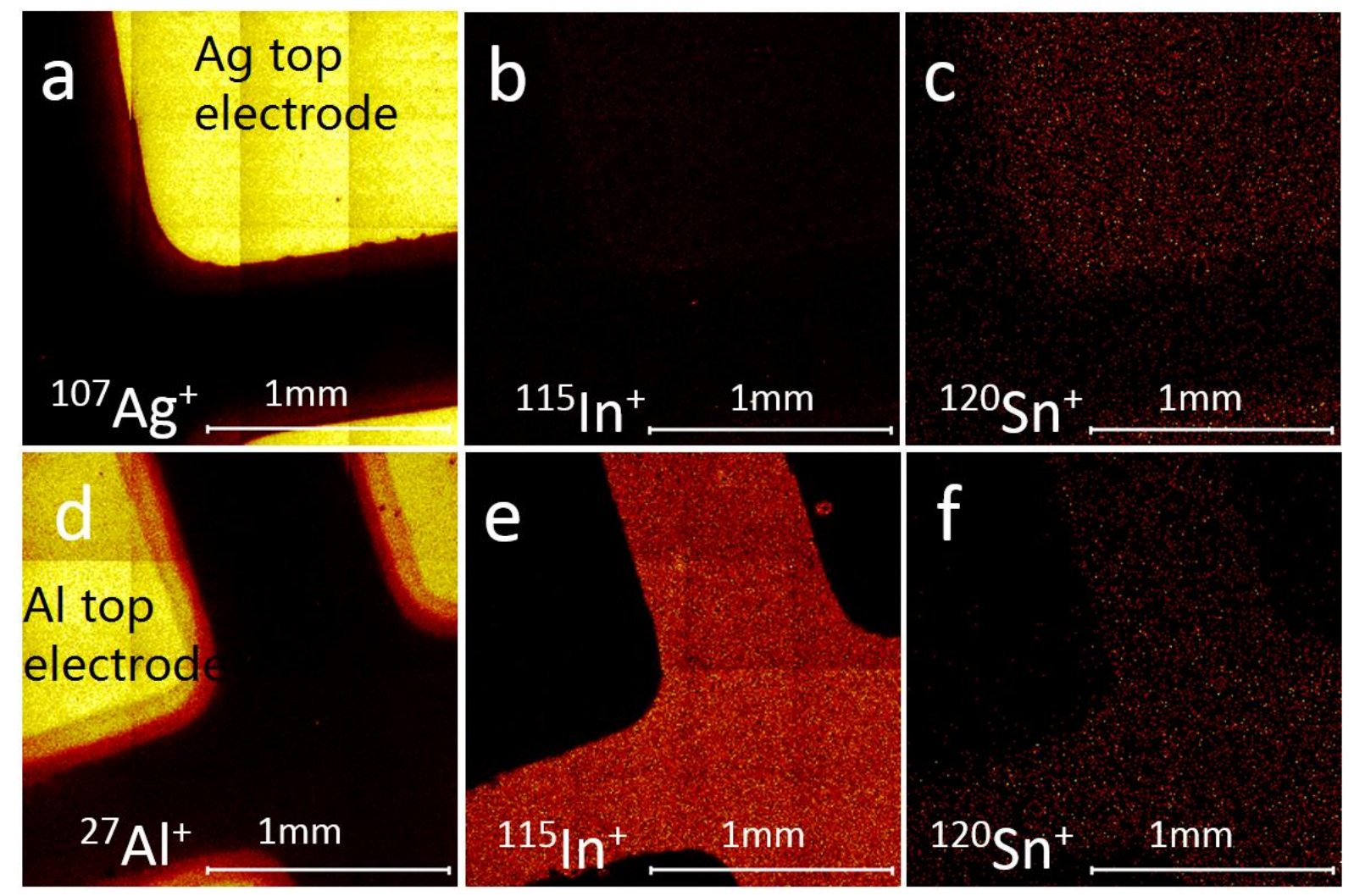

Figure 7: TOF-SIMS images show the ion distribution of ${ }^{107} \mathrm{Ag}^{+}(\mathrm{a}) ;{ }^{115} \mathrm{In}^{+}(\mathrm{b})$ and ${ }^{120} \mathrm{Sn}^{+}$(c) on the surface of an inverted cell aged in air for 300 hours and the distribution of ${ }^{27} \mathrm{Al}^{+}(\mathrm{d}) ;{ }^{115} \mathrm{In}^{+}$(e) and ${ }^{120} \mathrm{Sn}^{+}$(f) on the surface of a non-inverted cell aged in air for 300 hours.

\begin{tabular}{|l|l|l|l|l|}
\cline { 2 - 5 } \multicolumn{1}{c|}{} & \multicolumn{4}{c|}{ PCPDTBT, Atom \% concentration } \\
\cline { 2 - 5 } \multicolumn{1}{c|}{} & 0 hours & 25 hours & 100 hours & 300 hours \\
\hline C 1s & 86.52 & 78.04 & 62.07 & 60.58 \\
\hline N 1s & 4.03 & 4.49 & 6.04 & 6.28 \\
\hline S 2p & 9.2 & 7.71 & 6.45 & 6.27 \\
\hline O 1s & 0.25 & 9.75 & 25.44 & 26.87 \\
\hline
\end{tabular}

Table 1: The relative atomic concentrations in PCPDTBT, at 0, 25, 100 and at 300 hours

\begin{tabular}{|l|l|l|l|l|}
\cline { 2 - 5 } \multicolumn{1}{c|}{} & \multicolumn{4}{c|}{$\mathrm{PC}_{71} \mathrm{BM}$, Atom \% concentration } \\
\cline { 2 - 5 } \multicolumn{1}{c|}{} & 0 hours & 25 hours & 100 hours & 300 hours \\
\hline C 1s & 96.34 & 84.87 & 78.03 & 78.52 \\
\hline N 1s & - & 0.33 & 0.60 & 1.06 \\
\hline S 2p & 0.06 & 0.01 & 0 & 0.16 \\
\hline O 1s & 3.60 & 14.79 & 21.38 & 20.26 \\
\hline
\end{tabular}

Table 2: The relative atomic concentration of $\mathrm{PC}_{71} \mathrm{BM}$, at $0,25,100$ and at 300 hours 


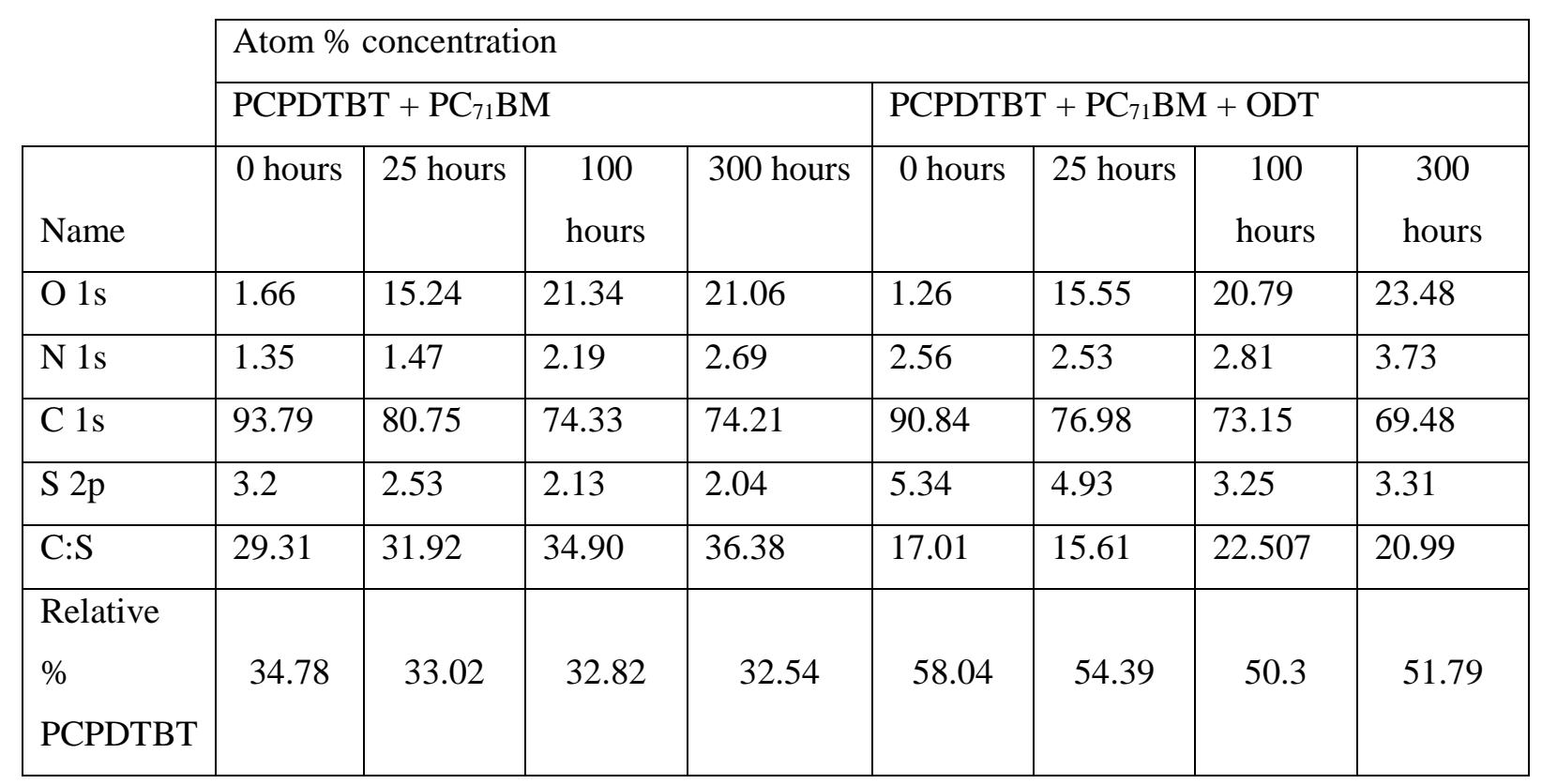

Table 3: Shown are the relative atom concentration of PCPDTBT $+\mathrm{PC}_{71} \mathrm{BM}$ and $\mathrm{PCPDTBT}+\mathrm{PC}_{71} \mathrm{BM}$ with ODT for both samples at $0,25,100$ and 300 hours of light soaking. Also show are the C:S ratio and the $\%$ of PCPDTBT present at the top surface of the active layer for fresh blends and aged blends.

\begin{tabular}{|l|l|l|l|l|}
\hline & $\mathrm{V}_{\mathrm{OC}}(\mathrm{V})$ & $\mathrm{J}_{\mathrm{SC}}\left(\mathrm{mA} / \mathrm{cm}^{2}\right)$ & $\mathrm{FF}$ & PCE (\%) \\
\hline $\begin{array}{l}\text { Inverted (with } \\
\text { ODT) }\end{array}$ & $0.609 \pm 0.01$ & $-13.78 \pm 0.9$ & $48.5 \pm 0.4$ & $4.07 \pm 0.18$ \\
\hline $\begin{array}{l}\text { Non-inverted } \\
\text { (with ODT) }\end{array}$ & $0.620 \pm 0.01$ & $-13.30 \pm 1.0$ & $47.5 \pm 0.5$ & $3.92 \pm 0.15$ \\
\hline $\begin{array}{l}\text { Inverted (no } \\
\text { ODT) }\end{array}$ & $0.580 \pm 0.01$ & $-7.57 \pm 0.4$ & $40.5 \pm 0.34$ & $1.76 \pm 0.15$ \\
\hline $\begin{array}{l}\text { Non-inverted (no } \\
\text { ODT) }\end{array}$ & $0.595 \pm 0.01$ & $-7.22 \pm 0.4$ & $39.6 \pm 0.5$ & $1.70 \pm 0.12$ \\
\hline
\end{tabular}

Table 4; Initial photovoltaic performance parameters of the inverted and non-inverted devices used for testing in section 4.1. Devices were measured using AM1.5G, with the light source calibrated with a reference cell supplied by ReRa Solutions BV. 